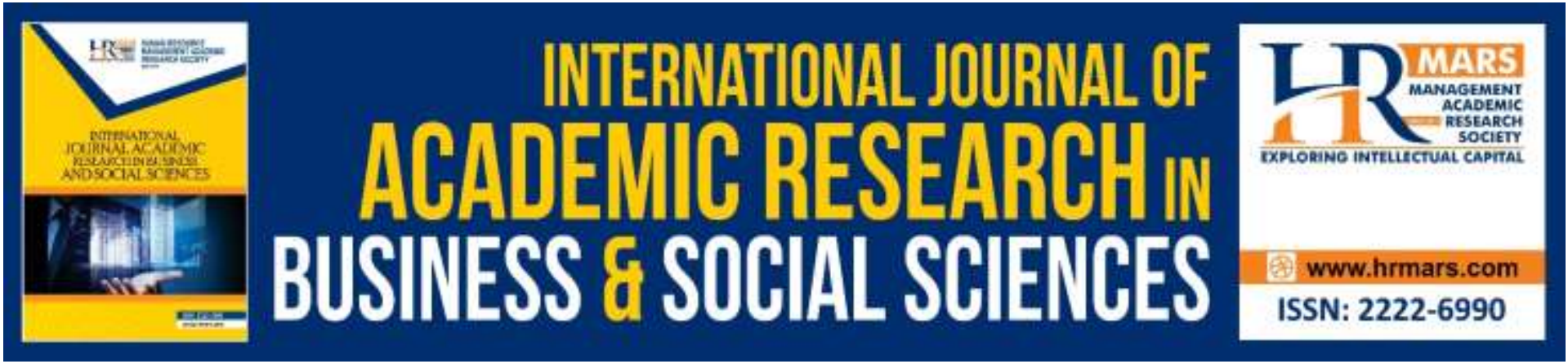

\title{
Examining University Students' Reading Performances and Behaviors with the Use of Eye-Trackers
}

\author{
Sarah Yusri, Or-Kan, Soh
}

To Link this Article: http://dx.doi.org/10.6007/IJARBSS/v9-i8/6221

DOI: $10.6007 /$ IJARBSS/v9-i8/6221

Received: 02 June 2019, Revised: 27 June 2019, Accepted: 01 August 2019

Published Online: 23 August 2019

In-Text Citation: (Yusri \& Soh, 2019)

To Cite this Article: Yusri, S., \& Soh, O.-K. (2019). Examining University Students' Reading Performances and Behaviors with the Use of Eye-Trackers. International Journal of Academic Research in Business and Social Sciences, 9(8), 114-123.

Copyright: (C) 2019 The Author(s)

Published by Human Resource Management Academic Research Society (www.hrmars.com)

This article is published under the Creative Commons Attribution (CC BY 4.0) license. Anyone may reproduce, distribute, translate and create derivative works of this article (for both commercial and non-commercial purposes), subject to full attribution to the original publication and authors. The full terms of this license may be seen at: http://creativecommons.org/licences/by/4.0/legalcode

\section{Vol. 9, No. 8, 2019, Pg. 114 - 123}

Full Terms \& Conditions of access and use can be found at http://hrmars.com/index.php/pages/detail/publication-ethics 


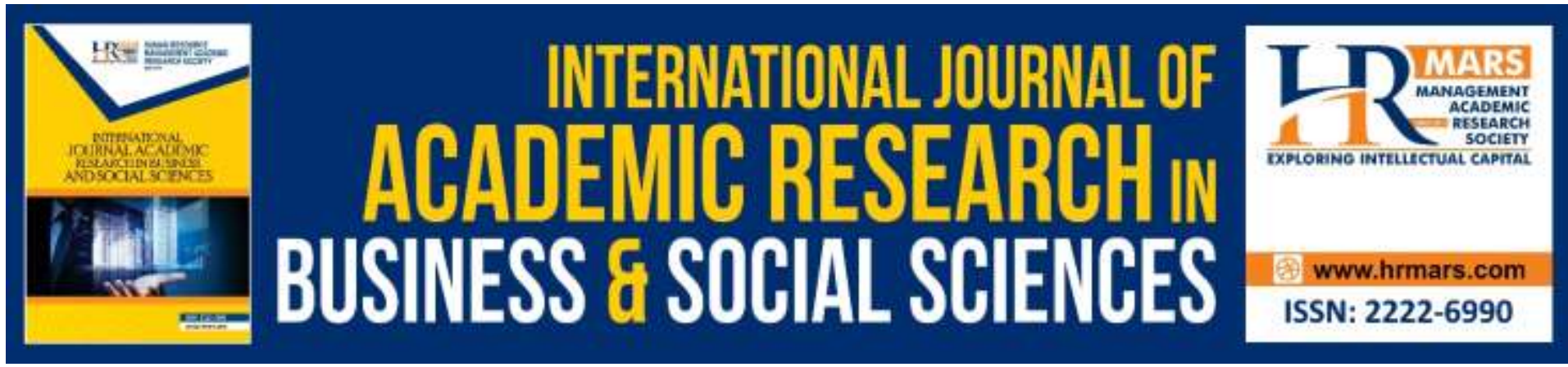

\title{
Examining University Students' Reading Performances and Behaviors with the Use of Eye-Trackers
}

\author{
Sarah Yusri, Or-Kan, Soh \\ School of Language Studies \& Linguistics, Faculty of Social Sciences \& Humanities \\ Universiti Kebangsaan Malaysia (UKM)
}

\begin{abstract}
The primary aim of the study was to examine Malaysian students' reading behaviours and performances. A total of twenty-one participants took part in this study. Participants were segregated into two different reading proficiencies: high and low. Findings from the reading passage and comprehension questions are calculated and analysed. The high proficient readers initial processing time were much longer in reading passage as compared to reading comprehension question, while the low proficient readers had shorter processing time during passage reading, but longer in reading comprehension question. During late processing time the high group indicated that their rates were smaller than the low proficient readers. The finding showed that there are significant different between reading behaviour of high and low proficient readers. An eyetracker was used to collect data.
\end{abstract}

Keywords: Reading Behaviour, High And Low Proficient Readers, Eye Movement.

\section{Introduction}

Eyetracking research enables us to investigate the deeper ends of the human mind because it takes a glimpse of what is happening internally of the brain processes and decoding before, during and after reading. The use of eye tracking within the context of reading makes it possible for researchers to depict both the readers' performance and competence. The outcomes have deeper understanding of the human condition on how readers digest, input and decode all information that they have taken from the lens of their eye (Conklin \& Pellicer-Sanchez, 2016). Greaney (2010) has claimed that reading behaviours exhibited by readers are able to be detected with an eyetracker, which measures and indicate information of the readers during reading. The eye-tracking is able to track where readers are focused on which is known as fixation, when readers have backtrack called as saccades, or how long readers read a certain lexis known as gaze duration and where readers focused or interested on when reading called as heat maps. Generally, eye-tracking tracks how fast a learner read, 
how much did a reader read, what the reader read and how well the reader read the text.

Besides, reading is intention of using strategies to increase comprehension of reading while comprehension reading is the ability to process the text, understanding what it means and integrate with what the readers already know (Broek \& Espin, 2012). In understanding what is read readers need to use various reading strategies to suit reading text types and difficulty. However, previous studies mentioned that readers even though they have knowledge about reading strategies, but they could not apply the strategies during reading (Saricoban, 2002). He suggested that educators such be able to develop reader' reading strategies. Furthermore, researchers have construct specific reading strategies to cater to L2 readers' different reading proficiencies and problems. Although Soh $(2016,2017)$ and Warid, Hazita and Soh (2018) have portrayed the evidence on the strategies used by high and low proficient readers, these two studies have not yet substantiate the evidence on university students. Hence, this study aimed at investigating students in a university who possess high and low reading metacognition with the use of eye-movement technology. This study will give more accurate data about the reading strategies used by students.

\section{Literature Review}

\section{Reading Behaviors of High and Low Proficient Readers with the use of Eye-Tracker}

In previous studies, they had found similar characteristic of high and low proficient readers based on the eye tracking metric of fixation duration. It is found that the fixation duration of high proficient readers is relatively longer than the fixation duration of low proficient readers in overall reading (Bax \& Chan 2016). When conducting MCQ or comprehension questions, the high proficient readers have shorter fixation duration as compared to low proficient readers to having longer fixation durations. Furthermore, in discussing of the second metric, fixation count, it is notably obvious when there is longer fixation duration, there will be more fixation count.

Saccades length in discuss to understand the way readers read and to get to know where readers place their eye during reading. Raney (2014) mention that the saccade length varies due to unfamiliarity and uncommonness of the sentences encountered. Regression is another metric discussed within eye tracking or the oculomotor dimension. Although reading comprehension research did not mention on regression, other research on reading have mentioned regression as criteria. In addition, Soh (2016) mentioned that when uncommon text or words appear during reading, readers are unable to comprehend thus result to having longer rereading time, shorter saccades length, longer fixation duration and longer gaze duration as compared to reading common text or common word. Hence, reading proficiency plays a vital role in decoding the information.

\section{Differences between High and Low Proficient Readers in Malaysia}

Studies in Malaysia has categorized high and low proficient readers mostly based on and inventory proposed by Mokhtari \& Reichard (2000). The differences between high and low proficient readers within Malaysia are (1) readers regardless being high or low proficiency utilize reading strategies, (2) readers utilize more problem-solving 
strategies are more successful in reading and (3) readers regardless of proficiency level gain beneficial advantages in the use of reading strategies. In hypothesis this means that the more strategy applied during reading meant more success in reading. The characteristics are explained below.

In reading, all readers regardless being high or low proficiency, they utilize all the three different elements of reading strategies. As readers in Malaysia are L2 or multilingual learners. It is common for readers to adopt much more strategies as compared to studies done abroad. Jafarigohar \& Khanjani (2014), Rajab et al. (2017) and Amal et al. (2017) have carried out research and determined that students employed different reading strategies such as problem-solving, global and support strategies when reading a text. Ruhil Amal et al. (2017) further mentioned the use of problem solving were able to make understanding for readers when they are confronted with difficulties during reading, while support strategies aids readers in maintaining an intact relation of the idea of the text being read.

It has shown that whether readers are of high or low proficiency, reading strategies are able to aid them in reading. Marimuthu et al. (2011) and Jusoh \& Abdullah (2016) have stated that reading strategies had positive impact on the readers' achievement. As high readers are sorted to use more frequency of reading strategies, it mentions that the more utilization of strategies lead to more success in reading. As being a second or multilingual readers, the target language may impose certain difficulties especially in understanding new vocabulary, thus the employment of vast strategies enables readers to crack open the treasure chest or the puzzle and putting those information into used so that the ideas all fit within the purpose of reading. Mehar Singh et al. (2012) mentioned that the use of reading strategy is useful for fostering independent readers and to improve language proficiency.

\section{Research Designs}

\section{Participants}

The participants of this study comprise first year students from the Faculty of Social Sciences and Humanities (FSSK), Universiti Kebangsaan Malaysia (UKM). A total of 21 participants took part in this research. Table 1 showed the distributions of readers with different reading abilities. The average age of all the participants was 21.45 years (SD.95). Before the experiment, all the participants were required to sit for a reading screening test (Ko \& Chan, 2006). It yielded a Cronbach's coefficient of.85.

\section{Reading Materials}

The reading materials was taken from Malaysia University English Test (MUET). The researcher made used of only one passage from the MUET reading texts without reducing the content of the texts. MUET reading passage comprises of one non-linear passage and 5 linear passages, followed by multiple choice questions (MCQ). The selection of one of the text is as a representation of the MUET reading. Field (2012) mentioned that the validity of reading text for language testing is based on three criteria; (1) similarity of the processing, means the passage adopt is similar to the 
target context (2) comprehensiveness, employment of cognitive process that participants would employ in natural context and the last one (3) calibration.

\section{Apparatus}

Eye-movement of participants are analyse using Tobii TX300. It is a non-intrusive eyetracker with $300 \mathrm{~Hz}$ sampling rate. The advantages of employing Tobii TX300 is due to its flexibility as it allows head movements, capable of tracking the participants' eye movement for long period of time without making them feel tired and the tracker is very sensitive to track and detect the movement of the eye from one word to another word or from a word to a character. The rate was selected to $60 \mathrm{~Hz}$ per second, which allows detailed tracking of normal reading.

\section{Results}

\section{Results for the Reading Comprehension Test}

Participants were required to read one passage followed by 7 comprehension questions. The finding of this data is calculated by means (M) and standard deviation (SD) to show the overall performance of the participants based on the two categories; high and low proficiency.

Table 1

Comprehension Results

\begin{tabular}{|l|c|c|c|}
\hline & $\begin{array}{c}\text { Correct Answer } \\
(\mathrm{M})\end{array}$ & $\begin{array}{c}\text { Wrong Answer } \\
\text { (M) }\end{array}$ & SD \\
\hline High proficiency readers & 8.14 & 2.86 & 1.07 \\
\hline Low proficiency readers & 6.14 & 3.86 & 2.41 \\
\hline
\end{tabular}

Table 1 showed high proficiency of the language lead to higher scoring rate. The difference in mean between high and low proficient readers is 2 , where high proficient readers has a mean of 8.14 and low proficient readers has a mean of 6.14. Where in contrast, the low proficient readers had answered more wrong answers compared to the high proficient readers. Thus, the table depicts that proficiency of language affect the performance of language.

\section{Participants Eye Movements' Metrics}

Finding for eye tracking metrics is divided into 8 area of interest (AOIs). The first is the reading passage followed by the seven reading comprehension questions. All 21 participants' eye movement are accounted. Within this section, the finding is partition into two; the eye metrics during reading and the eye metrics during comprehension questions. The researcher then analysed the eye-movement in two processes which are the initial processing and the late processing. Initial processing is simply the basic measure such as first fixation time, whereas late processing is regression. Before the data is collected, the researcher highlighted the area of interest (AOIs). All data from the eye tracker are within the AOIs. The data are calculated, analysed and presented into mean (M) and standard deviation (SD) which adapted from previous researchers 
(Bax 2013a; Bax 2013b and Bax 2016). The measurement for the eye metrics are all in seconds (s).

Initial Processing Time during Reading

Table 2

FIRST FIXATION DURATION

\begin{tabular}{|l|c|c|c|c|}
\hline \multirow{2}{*}{ AOls highlighted } & \multicolumn{2}{|c|}{ High proficient readers } & \multicolumn{2}{c|}{ Low proficient readers } \\
\cline { 2 - 5 } & $\mathbf{M}$ & $\mathbf{S D}$ & $\mathbf{M}$ & $\mathbf{S D}$ \\
\hline Title & 0.21 & 0.10 & 0.20 & 0.06 \\
\hline $1^{\text {st }}$ Paragraph & 0.15 & 0.07 & 0.15 & 0.06 \\
\hline $1^{\text {st }}$ Header & 0.16 & 0.06 & 0.23 & 0.13 \\
\hline $2^{\text {nd }}$ Paragraph & 0.12 & 0.06 & 0.18 & 0.09 \\
\hline $2^{\text {nd }}$ Header & 0.24 & 0.09 & 0.15 & 0.06 \\
\hline $3^{\text {rd }}$ Paragraph & 0.22 & 0.11 & 0.16 & 0.06 \\
\hline $3^{\text {rd }}$ Header & 0.20 & 0.11 & 0.21 & 0.09 \\
\hline $4^{\text {th }}$ Paragraph & 0.21 & 0.11 & 0.21 & 0.08 \\
\hline $4^{\text {th }}$ Header & 0.19 & 0.10 & 0.26 & 0.14 \\
\hline $5^{\text {th }}$ Paragraph & 0.17 & 0.08 & 0.16 & 0.07 \\
\hline $5^{\text {th }}$ Header & 0.16 & 0.07 & 0.17 & 0.09 \\
\hline $6^{\text {th }}$ Paragraph & 0.15 & 0.04 & 0.17 & 0.06 \\
\hline
\end{tabular}

Table 2 shows that readers with high proficiency have longer first fixation duration as compared to readers with low proficiency. Only in certain AOls that readers of low proficiency took longer, however, the difference between them were not that much with having $S D=0.02$ to $S D=0.07$ in difference. Readers of low proficiency took a longer time to read in the 2nd paragraph and the last paragraph, whereas the high proficiency readers mirrored the action of the low proficient readers and took shorter first fixation duration.

Late Processing Time during Reading

Table 2

Rereading Rates

\begin{tabular}{|l|c|c|c|c|}
\hline \multirow{2}{*}{ AOls highlighted } & \multicolumn{2}{|c|}{ High proficient readers } & \multicolumn{2}{c|}{ Low proficient readers } \\
\cline { 2 - 5 } & $\mathbf{M}$ & $\mathbf{S D}$ & $\mathbf{M}$ & SD \\
\hline Title & 3.60 & 2.17 & 5.33 & 3.32 \\
\hline $1^{\text {st }}$ Paragraph & 37.55 & 5.15 & 53.00 & 23.18 \\
\hline $1^{\text {st }}$ Header & 2.30 & 1.57 & 6.50 & 5.15 \\
\hline $2^{\text {nd }}$ Paragraph & 115.55 & 66.49 & 175.70 & 39.38 \\
\hline $2^{\text {nd }}$ Header & 3.45 & 1.86 & 5.10 & 3.96 \\
\hline $3^{\text {rd }}$ Paragraph & 84.27 & 35.70 & 85.10 & 30.29 \\
\hline $3^{\text {rd }}$ Header & 3.50 & 2.72 & 2.89 & 1.76 \\
\hline $4^{\text {th }}$ Paragraph & 60.40 & 39.24 & 69.50 & 49.58 \\
\hline $4^{\text {th }}$ Header & 5.60 & 2.72 & 9.67 & 6.02 \\
\hline $5^{\text {th }}$ Paragraph & 60.73 & 31.71 & 66.40 & 37.38 \\
\hline $5^{\text {th }}$ Header & 7.18 & 4.26 & 9.40 & 4.53 \\
\hline $6^{\text {th }}$ Paragraph & 70.82 & 40.23 & 91.20 & 17.14 \\
\hline
\end{tabular}


Table 2 showed the low proficiency group' rereading rates were much higher than the high proficiency readers. The top three highest AOls by the low proficient readers are the 2 nd paragraph $M=175.70$ s followed by 6th paragraph with $M=91.20$ s and 3rd paragraph with $\mathrm{M}=85.10 \mathrm{~s}$. In comparison, the high proficiency readers top three highest AOls are the 2nd paragraph $M=115.55 \mathrm{~s}$, 3rd paragraph $M=84.27 \mathrm{~s}$ and 6 th paragraph $\mathrm{M}=70.82 \mathrm{~s}$. The least rereading AOls for the low proficient readers is the 3rd header; don't smoke, whereas the lowest rereading rate for high proficient readers is the 1 st header $M=2.30$ s.

Table 3

Regression Rate for High and Low Reading Proficiency

\begin{tabular}{|l|c|c|}
\hline \multicolumn{1}{|c|}{ Regression rates } & Percentage & SD \\
\hline High proficient readers & $34.96 \%$ & 0.05 \\
\hline Low proficient readers & $37.63 \%$ & 0.06 \\
\hline
\end{tabular}

Table 3 the tendency of participants to regress during reading. It states that the percentage for high proficient readers to regress is $34.96 \%$ with an equivalent to $\mathrm{SD}=0.05$ as compared to the low proficient group with a percentage of $37.63 \%$ and $\mathrm{SD}=0.06$. This shows that the low proficient readers tend to have move eye backward movement as compared to the high proficient readers. The different in percentage between the two groups is $2.67 \%$.

\section{Discussion}

Findings showed that although low proficient readers only understand the text at the surface level. The do not make inference based on their prior knowledge. This is not the case in reading. Reading requires readers to make inference, to think about the information given and make self-inferences and opinion about the text. The construction of these inferences are difference from one reader to another as readers then to face difference experience differently. Although setting might be the same, but how readers perceives the information or construct it is different. It is in line with research done by Soh $(2016,2017)$ On the other hand, high proficient readers tend to approach text similarly and not taking various step to find the answers. Reading requires one to use various means to understand a text. Reading is not reading when readers only read at text level. Readers become wiser with reading, when they read, make inference and come to a critical opinion about the text.

In this study, the findings have shown that the high proficient group have longer first fixation duration during passage reading but shorter duration during comprehension question, shorter fixation duration, longer total fixation duration, longer rereading rate during comprehension question but lower rereading rate when reading passage and lower regression rate for overall reading. On the other hand, the low proficient group have shorter first fixation duration, longer fixation duration, shorter total fixation duration, higher rereading rates during passage reading but shorter rereading rates during comprehension questions and highest regression rate for overall of reading. Previous research has also shown similar finding with this study 
(Bax, 2016). First fixation duration is a metric reflecting on the time taken for the participants to fix their sight on the selected area of interest for the first time. This occurrence is probably due to the low proficient readers having low cognitive processing which later the process of first fixation duration. In comprehension question activities, the high proficient are able to detect which paragraph to refer as an immediate respond, but the low proficient readers took a longer time to fixate their eyes on the designated paragraph to obtain the answers.

In opposite, the low proficient reader rereading rate was higher due to decipher of information is slow. The readers tend to reread during passage reading as an expression for them to understand the sentences and relate to the current read sentence. As being, second language readers, language is a barrier for them to understand, thus rereading is one way for them to think back, stop and continue processing the information and to confirms whether the information last process relate or in coherence with the next information. However, during the comprehension question, the low proficient reader reread less. This is a flaw in them. When answering the question, they take less time to reread and assume the answers when reading the located answer at first glance without rereading as a confirmation to the answers (Zaira, 2008).

During regression, the data showed that the low proficient readers were higher in regression rate as compared to the high proficient readers. Regression is a backward movement of the eye when reading a line of text. As mentioned by researcher Soh (2016) low proficient readers do regression more than high proficient readers because of wanting to check on things more repeatedly. Where they mentioned that when readers do not have prior knowledge, readers have the tendency of wanting to confirm ideology of the text, finding the definition of certain word and finding relation to what has been read.

\section{Conclusion}

This research recommends in future research to differentiate reading of adults with children to observe and analyses whether adults and children commit reading in a similar manner or different. Further research on the second language is vital as there are not many researches in this area yet. Thus, being in a multilingual country this research is possible to be carried out in the future. The researcher also suggest to carry this experiment with a larger scale of participants as this research only made the requirement with only 21 participants. The probability with a larger scale of participants will make the data more lively and robust. This study will give knowledge to educators to prepare their materials for different levels of students.

\section{References}

Bax, S. \& Chan, S. H. C. (2016). Researching the cognitive validity of GEPT highintermediate and advance reading an eye-tracking and stimulated recall study. The Language Training and Testing Centre (LTTC).

Conklin, K. \& Pellicer-Sanchez, A. (2016). Using eye-tracking in applied linguistics and second language research. Second Language Research, 1-15. 
Greaney, S. (2011). Comparing the reading behaviors in three groups of first grade students-students who discontinued from Reading Recovery, students who did not discontinue from Reading Recovery, and students who never needed Reading Recovery (Unpublished doctoral dissertation). University of Maine, Orono.

Jafarigohar, M., \& Khanjani, A. (2014). Text difficulty effect on metacognitive reading strategies used among EFL learners. Journal of Language Studies, 14(2), 47-59.

Jusoh, Z. and Abdullah, L. (2015), Online Survey of Reading Strategies (OSORS): Students' Online Reading in Academic Context, Malaysian Journal of Distance Education, 17(2): 67-81.

Singh, M. K., Rowena, A. D. \& Choo, S. J. (2012). Sustained silent reading (SSR) as an independent learning tool at an institution of higher learning. Ubiquitous Learning: An International Journal, 4(1), 77-89.

Rajab, A., Rahman, A. H., Wahab, A. S. R., Nor, M. F., Zakaria, W. Z. \& Rajim, W. Z. (2017). Metacognitive reading strategies among undergradutes. International Journal of Information and Education Technology 7(7), 548-551.

Raney, G. E., Campbell, S. J. \& Bovee, J. C. (2014). Using eye movements to evaluate the cognitive processes involved in text comprehension. Journal of Visual Education, 507-580.

Amal, R. A., Fariza, N. M. N. \& Afendi, H. (2017). Metacognitive online reading and navigation strategies by science and technology university students. GEMA Online Journal of Language Studies, 17(3), 18-36.

Sarıçoban, A. (2002). Strategies of Successful Readers through the Three-Phase Approach. The Reading Matrix, 2 (3), September Issue.

Soh, O. K. (2016). Examining the reading behaviours and performances of sixthgraders for reading instruction: evidence from eye movements. Journal of eLearning and Knowledge Society, 12(4),. Italian e-Learning Association. Retrieved May 14, 2019 from https://www.learntechlib.org/p/173674/.

Soh, Or-Kan. (2017). Processing Academic Science Reading Texts through Context Effects: Evidence from Eye Movements. EURASIA Journal of Mathematics Science and Technology Education, 13(3):771-790. DOI 10.12973/eurasia.2017.00642a

Mihat, W., Azman, H. \& Soh, O. K. (2018). Bringing reading research in multilingual Nusantara into a new direction through eye-tracking. Journal of Nusantara Studies, 3(2), 107-123. http://dx.doi.org/10.24200/jonus.vol3iss2pp107-123

Marimuthu, R \& Muthusamy, C. (2011). “Metacognitive Strategy Training through The Cognitive Academic Language Learning Approach (CALLA) as a Way to Improve Reading Comprehension Performance among Students of an English Language Course at UiTM Penang". Malaysian Journal of ELT Research. Vol. 7, No. 1, hal. 64-93, 2011.

Mokhtari, K. \& Reichard, C. A. (2002). Assessing students' metacognitive awareness of reading strategies. Journal of Educational Psychology, 94(2): 249-259.

Broek, V. D. P., \& Espin, C. A. (2012). Connecting cognitive theory and assessment: Measuring individual differences in reading comprehension. School Psychology Review, 41, 315-325.

Zaira, A. H. (2008). Peer interaction and meaning construction among ESL learners in 
INTERNATIONAL JOURNAL OF ACADEMIC RESEARCH IN BUSINESS AND SOCIAL SCIENCES Vol. 9, No. 8, August, 2019, E-ISSN: 2222-6990 @ 2019 HRMARS

comprehending texts in 2nd language context. Unpublished PhD thesis. Faculty of Modern Languages, Universiti Putra Malaysia (UPM), Serdang. 